\title{
A unique mating pattern of Panorpodes kuandianensis (Mecoptera: Panorpodidae)
}

\author{
Xin Tong ${ }^{1}$, Lu Jiang ${ }^{1,2}$, Bao-Zhen Hua ${ }^{1,3}$ \\ ${ }^{1}$ State Key Laboratory of Crop Stress Biology for Arid Areas, Key Laboratory of Plant Protection Resources and \\ Pest Management, Ministry of Education, Entomological Museum, Northwest A\&F University, Yangling, Shaanxi \\ 712100, China \\ ${ }^{2}$ Key Laboratory of Economic and Applied Entomology of Liaoning Province, College of Plant Protection, Shen- \\ yang Agricultural University, Shenyang, Liaoning 110866, China \\ ${ }^{3}$ E-mail: huabzh@nwafu.edu.cn
}

Key words: copulatory mechanism, mating behavior, nuptial gift, sexual conflict, genital morphology

\begin{abstract}
Sexually reproductive insects exhibit diverse mating behaviors. However, the mating pattern remains unknown for Panorpodes of Panorpodidae to date. In this study, we investigated the mating behavior and copulatory mechanism of the short-faced scorpionfly Panorpodes kuandianensis Zhong, Zhang and Hua, 2011 for the first time. The results show that the male provides a salivary mass as a nuptial gift to the female and starts to copulate with the female in a V-shaped position, then changes to an end-to-end position by temporarily twisting the female abdominal segments VII-IX by $180^{\circ}$. During mating the basal processes and the basal teeth of the gonostyli and the hypandrium are used to obtain copulation and sustain the coupling of genitalia to secure successful sperm transfer. This unique mating pattern is greatly different from that of other Mecoptera reported and is likely evolved as an adaptation in the context of sexual conflict.
\end{abstract}

\section{Contents}

\begin{tabular}{|c|c|}
\hline Introduction . & 229 \\
\hline Material and Methods & 230 \\
\hline Insect collection .... & 230 \\
\hline Insect rearing ............... & \\
\hline Mating behavior observation ........... & \\
\hline 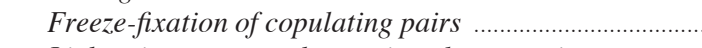 & \\
\hline Light microscopy and scanning electron microscopy ... & 230 \\
\hline Results ............................ & \\
\hline Mating behavior .................... & \\
\hline Male and female genitalia ............ & \\
\hline Coupling of the genitalia ................ & \\
\hline Copulatory mechanism .............. & \\
\hline Torsion of the female abdomen & \\
\hline Discussion ........................................... & \\
\hline Acknowledgements . & \\
\hline References …...... & \\
\hline
\end{tabular}

\section{Introduction}

The vast majority of sexually reproductive animals propagate through mating. For insects diverse mating positions have evolved to deliver sperm ejaculates, with the female-above pattern as the groundplan (Huber et al., 2007; Huber, 2010), from which all other deviations evolved through rotations or flexions of the terminal abdomen of males (McAlpine et al., 1981; Bickel, 1990; Huber, 2010). The evolution of mating position and other behavioral traits involved in mating are regarded to relate to sexual conflict in insects (Chapman et al., 2003; Parker, 2006).

Most Mecoptera are characterized by their interesting sexual behaviors, including various mating positions, nuptial feeding or forced copulation by modified grasping devices (Thornhill, 1973, 1980, 1981; Thornhill and Sauer, 1991; Sauer et al., 1998; Engqvist and Sauer, 2001, 2003; Byers, 2002; Engqvist, 2007, 2009, 2011; Kock et al., 2009; Gao and Hua, 2013; Zhong and Hua, 2013; Zhong et al., 2015a, b). Of the nine families, five have been studied with respect to their mating behaviors and/or copulatory mechanisms (Cooper, 1974; Thornhill, 1981; Byers and Thornhill, 1983; Thornhill and Sauer, 1991; Ma et al., 2010; Zhong and Hua, 2013; Zhong et al., 2015a, b). The male of Boreidae uses his paired hook-shaped wings to secure the female dorsally to form a typical female-above mating position (Cooper, 1974). In Bittacidae the male temporarily twists his abdomen by $180^{\circ}$ to maintain a belly-to-belly mating position to control the nuptial gift (Gao and Hua, 2013). Most males of Panorpidae provide a salivary mass as a nuptial gift and sustain a $\mathrm{V}$-shaped mating 
position (Thornhill, 1981; Byers and Thornhill, 1983; Zhong et al., 2015a). The male of Panorpa liui Hua, 1997 offers the female only prey rather than salivary mass as a nuptial gift owing to the less-developed salivary glands of males (Ma and Hua, 2011). The species of Furcatopanorpa (Panorpidae) (Zhong et al., 2015b) and Chorista (Choristidae) (Byers and Thornhill, 1983) adopt an O-shaped mating position for the male lacking a notal organ to help control the female. Similarly in the males of Panorpodidae the notal organ is vestigial or thoroughly lacking (Carpenter, 1953; Byers and Thornhill, 1983; Tan and Hua, 2008; Zhong et al., 2011; Krzeminski and Soszynska-Maj, 2012), but their mating behavior has not been satisfactorily studied thus far.

Panorpodidae is the sister group of Panorpidae (Willmann, 1987; Friedrich et al., 2013), and consists of only 13 extant species in two genera: Brachypanorpa Carpenter, 1931 occurring in North America and Panorpodes MacLachlam, 1875 almost exclusively distributed in eastern Asia (Pollmann et al., 2008; Hu and Hua, 2016). Panorpodes colei Byers, 2005 from western North America is the only exception (Byers, 2005). The male of Brachypanorpa does not provide any nuptial gift, and starts mating with the female in a V-shaped mating position at any time of the day but usually in the evening (Carpenter, 1953; Byers, 1997). As far as we know, however, the mating behavior in Panorpodes has not been reported to date.

In this study, we investigated the mating behavior and copulatory mechanism of the short-faced scorpionfly Panorpodes kuandianensis Zhong, Zhang and Hua, 2011 and found an unusual mating pattern in Mecoptera.

\section{Material and Methods}

\section{Insect collection}

Adults of P. kuandianensis were collected at the Quanshan Forest Park $\left(41^{\circ} 06^{\prime} \mathrm{N}, 125^{\circ} 02^{\prime} \mathrm{E}\right.$, elev. $650-800$ $\mathrm{m})$, Kuandian County, Liaoning Province in northeastern China from early July to August in 2015 and 2016.

\section{Insect rearing}

Male and female adults were reared in three gauze cages $(40 \mathrm{~cm} \times 40 \mathrm{~cm} \times 60 \mathrm{~cm})$ in the laboratory under natural conditions following Zhong and Hua (2013). Absorbent cotton containing water was replaced each day in a Petri dish. Twigs with leaves were placed in the cages to simulate the habitat of the adults, and were replaced every three days. Each cage was supplied with five drops of honey per day to prevent low nutritional status (Jiang et al., 2014).

\section{Mating behavior observation}

Ten males and ten females were reared in each cage to investigate their mating behaviors. These adults were observed $24 \mathrm{~h}$ a day during 6-10 July 2015 to check the circadian rhythms of mating activity. Then adults were observed every $30 \mathrm{~min}$ from daybreak to noon to record the mating behaviors, including mating positions and copulatory processes. Photographs were taken with a Nikon D90 digital camera.

\section{Freeze-fixation of copulating pairs}

Pairs in copula were frozen through carbon dioxide aerosol spray compressed in hydraulic cans, and were immediately fixed in Carnoy's solution at room temperature for 24-48 $\mathrm{h}$ to stabilize the interactions of their genital structures and preserved in $75 \%$ ethanol.

\section{Light microscopy and scanning electron microscopy}

Fifty adults (30 males and 20 females) fixed in Carnoy's solution were dissected under a Nikon SMZ1500 microscope. Photographs were taken with a QImaging Retiga-2000R digital camera attached on the microscope and were stacked with the Syncroscopy AutoMontage software.

For scanning electron microscopy (SEM), the dissected genital structures were cleaned ultrasonically for $90 \mathrm{~s}$, and then dehydrated in a graded ethanol series, freeze-dried for $3 \mathrm{~h}$, coated with gold in a sputter coater, and examined in a Hitachi S-3400N scanning electron microscope (Hitachi, Tokyo, Japan) at $5 \mathrm{kV}$.

\section{Results}

\section{Mating behavior}

Thirteen pairs of P. kuandianensis were recorded to mate in the morning and three of them were frozen in copulation. The male provided a salivary mass to a nearby female and tried to attract her through vibrating his wings rapidly (Fig. 1a). Then he stretched out his paired gonostyli to grasp the abdominal end of the female, used his hypandrium to seize the female cerci and attempted to establish the connection of the genita- 

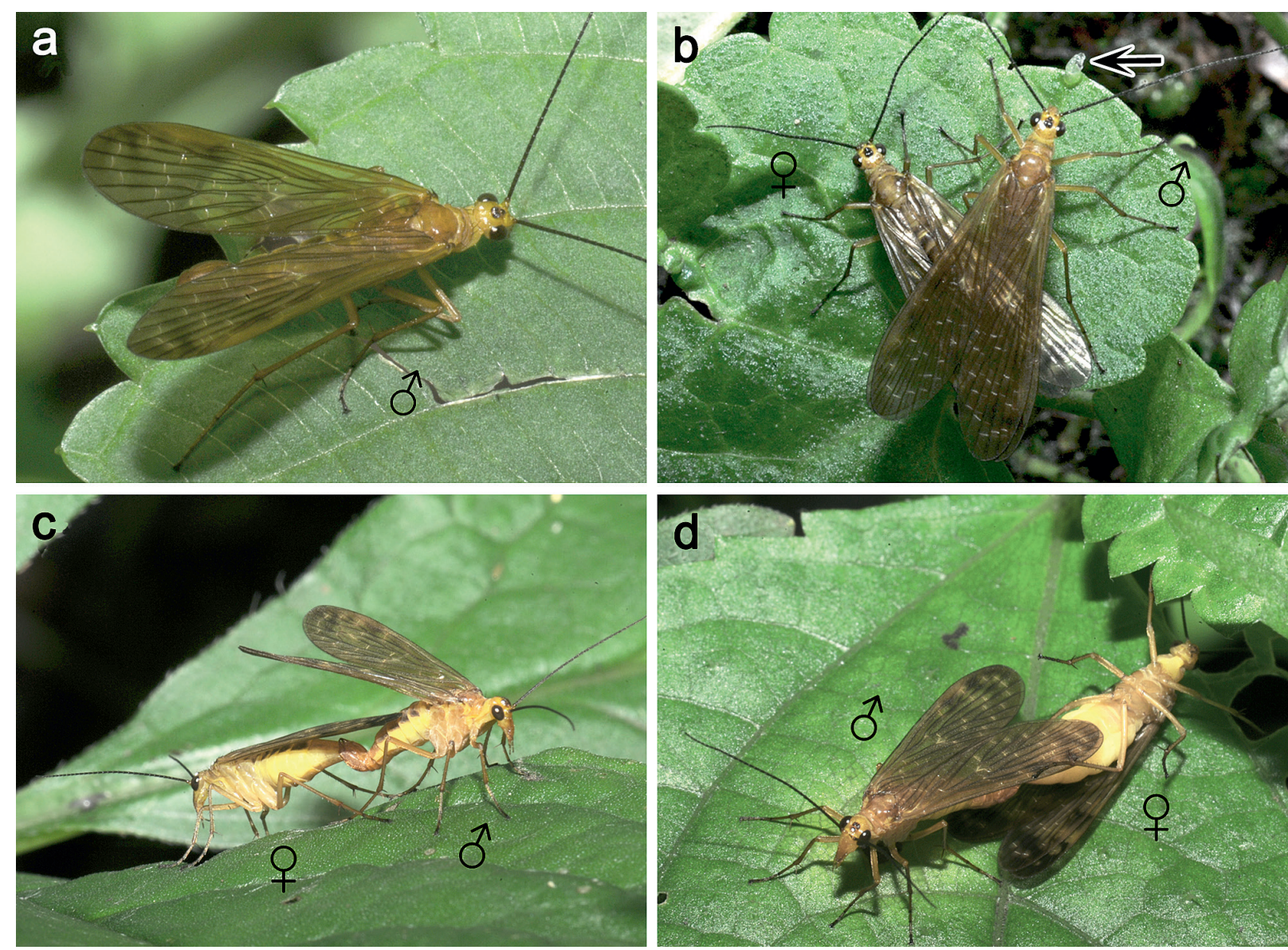

Fig. 1. Mating position of Panorpodes kuandianensis. a, a male is secreting a salivary mass as a nuptial gift; b, initial phase of copulation with the coupling pair sustaining a V-shaped position, arrow points at the salivary mass; c, stable phase of copulation, the coupling pair sustains an end-to-end position with the female abdomen twisted; d, final phase of copulation, the coupling pair sustains an end-to-end position with the female body inverted.

lia. Meanwhile, the female usually tried to get rid of the male control by wriggling her abdomen. To suppress the female resistance, generally, the male adjusted his posture and seized the female abdomen by the paired basal processes and the basal teeth to couple their genitalia and guarantee the sperm transfer. In the initial phase of copulation, the male randomly stood on one side of the female (six left-sided matings and seven right-sided matings) to sustain a V-shaped position with their genitalia coupled (Fig. 1b). While the female consumed the salivary mass, the male changed the mating position from the V-shape to an end-to-end position (Fig. 1c). The male kept on pulling the female till the end of copulation, and some females ( 2 of 10 ) were observed to invert their bodies before terminating copulation (Fig. 1d).

\section{Male and female genitalia}

The genital segment (abdominal segment IX, A9) of male $P$. kuandianensis consists of a dorsal epandrium (tergum IX), a ventral hypandrium (sternum IX), and the median genitalia (Figs 2a, b). The genitalia consist of a central aedeagus, a pair of parameres, and a pair of lateral gonopods (Fig. 2a). The gonopods are fused at the base, each comprising a basal gonocoxite and a distal gonostylus (Figs 2a, b).

The epandrium is broad basally and nearly parallel apically. Two short, round-tipped cerci are born on the lateral sides of abdominal segment XI (A11) and extend out from below the epandrium (Fig. 2b).

The hypandrium consists of a long broad basal stalk and a pair of short distal hypovalves (Figs 2e, f). Each 

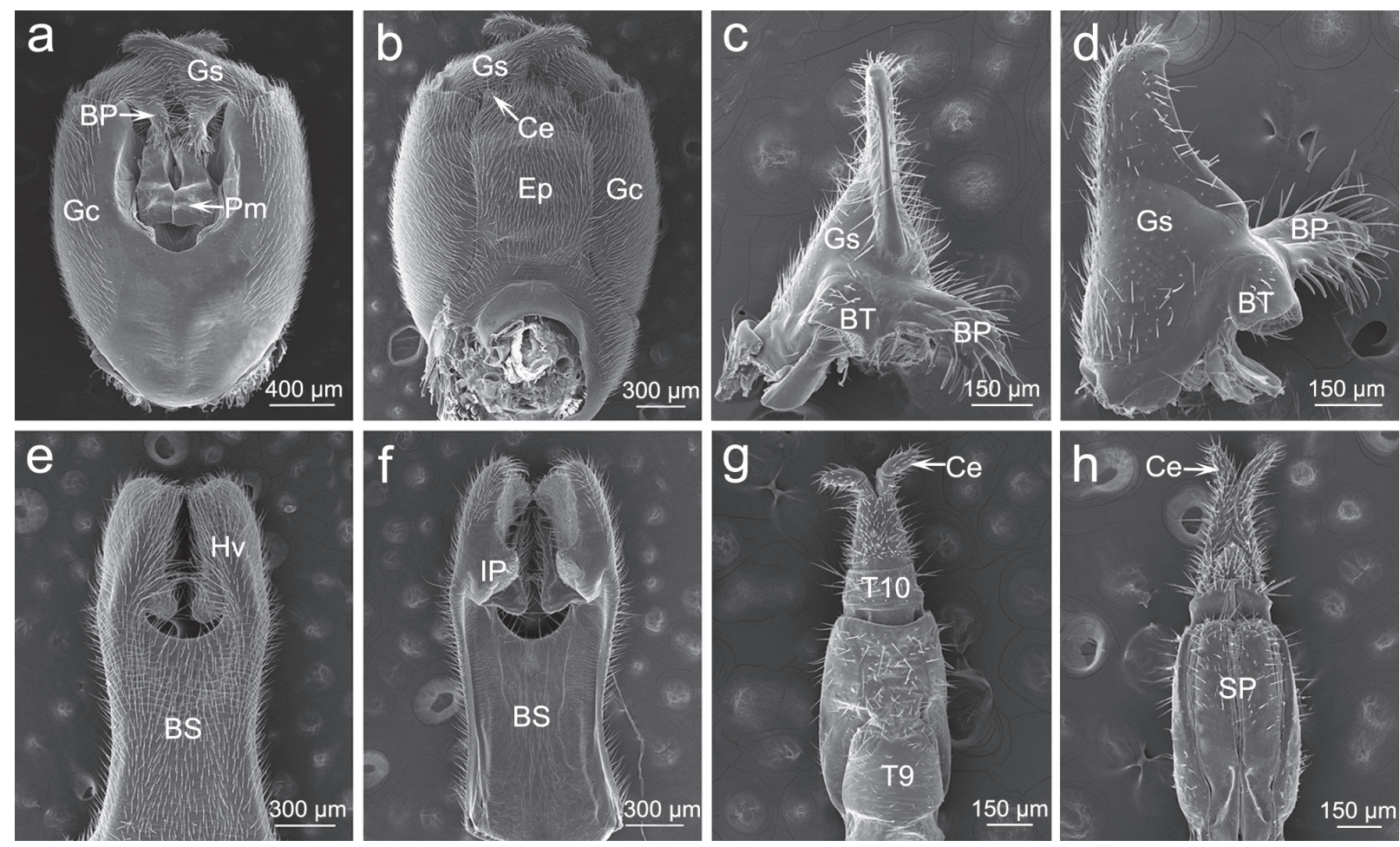

Fig. 2. Male and female genitalia of Panorpodes kuandianensis. a, male genital bulb in ventral view, with the hypandrium removed; b, the same, dorsal view; c, gonostylus, mesal view; d, gonostylus, dorsal view; e, hypandrium, ventral view; f, hypandrium, dorsal view; g, terminal end of female abdomen in dorsal view; h, the same, ventral view. BP, basal process; BS, basal stalk; BT, basal tooth; Ce, cercus; Ep, epandrium; Gc, gonocoxite; Gs, gonostylus; Hv, hypovalve; IP, incrassate process; Pm, paramere; SP, subgenital plate; T9-T10, tergum IX-X.

hypovalve has a rounded incrassate process, which is situated basally on the inner margin of the hypovalve and covered with spinules on the dorsal surface (Fig. 2f).

The paired gonocoxites fuse basally to form a Ushaped concavity from the middle part to accommodate the aedeagus centrally (Fig. 2a). Each gonostylus has a prominent lobe-like basal tooth and a well-developed finger-shaped basal process. The elongate basal process bears numerous conical sensilla (Figs 2c, d).

Each paramere is composed of an applanate ventral branch, a strongly-sclerotized dorsal branch with a lateral process arising from the middle part, and a slender basal stalk. The parameres cling to the aedeagus, so that the ventral branches are unable to stretch ventrally from the aedeagus (Figs 2a, 3b).

The aedeagus is an interconnecting organ of the male, and consists of a pair of ventral valves, a pair of dorsal valves, and a central phallotreme. The ventral valves are usually concealed by parameres (Figs 3a, b).

The female genitalia consist mainly of a genital plate and a subgenital plate (Figs 2g, h). The subgenital plate is oblong with two weakly-sclerotized sclerotomes (Fig. 2h). The two sclerotomes curve dorsally to form a genital chamber, inside which the genital plate is situated.

The female genital plate is a short strongly-sclerotized structure, situated at the base of the genital chamber. The orifice of the spermathecal duct is located ventrally at the sub-apical area of the genital plate distal to the sculptured area (Figs 3c, d).

\section{Coupling of the genitalia}

The claspers and other grasping devices of the male grasp the terminal end of the female abdomen to establish the coupling of the genitalia (Figs 4,5). The hypovalves with incrassate processes seize the female cerci and cause the cerci to bend dorsad (Figs 4, 5a, b). The finger-like basal processes of the male gonostyli clasp the rotated genital segments of the female (Figs 4a, 5b, d). The paired lobe-like basal teeth seize the rear area of the genital chamber (Figs 4b, 5c). 

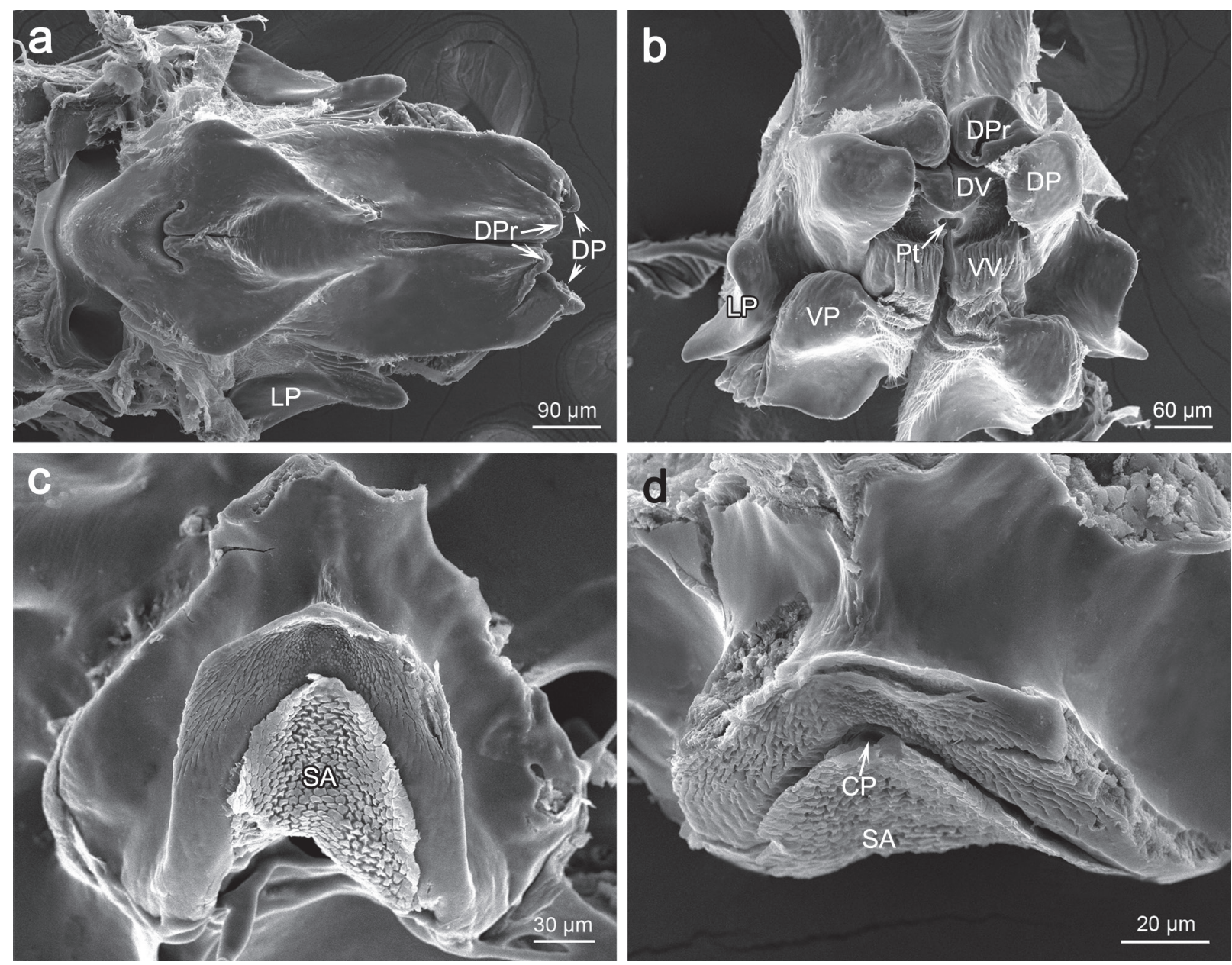

Fig. 3. Male aedeagus and female genital plate of Panorpodes kuandianensis. a, aedeagus, dorsal view; b, aedeagus, caudal view; c, genital plate, caudoventral view; d, genital plate, caudal view. CP, copulatory pore; DP, dorsal paramere; DPr, dorsal process; DV, dorsal valve; LP, lateral process; Pt, phallotreme; SA, sculptured area; VP, ventral paramere; VV, ventral valve.

\section{Copulatory mechanism}

When the female is under control, the male seizes her cerci with his hypovalves and opens her genital chamber. After that, the male inserts his aedeagus into her genital chamber, with the lateral membranes of the female A9 obstructing the paired lateral processes into the genital chamber (Fig. 4b). Then the male adjusts his posture, thus enabling the phallotreme to contact the copulatory pore of the female to deliver his sperm ejaculates into the female spermatheca. During copulation the male keeps the stability of genital connection by using the lobe-like basal teeth of his gonostyli to restrict the movement of the genital plate (Figs $4 b, 5 c$ ) and utilizing the basal processes of his gonostyli to pre- vent the female abdomen from shaking off the male control. The coupling genital structures mesh completely when the mating position changes from a Vshape to an end-to-end position.

\section{Torsion of the female abdomen}

The abdominal segments of female $P$. kuandianensis are unique in that the abdominal segments VII and VIII (A7 and A8) and the most part of A9 are usually concealed within abdominal segment VI (A6). In the process of position-change, the terminal abdomen of the female undergoes a rotation clockwise or anticlockwise (Figs 5c, d). The abdominal segments are recurved upward when the paired male and female 


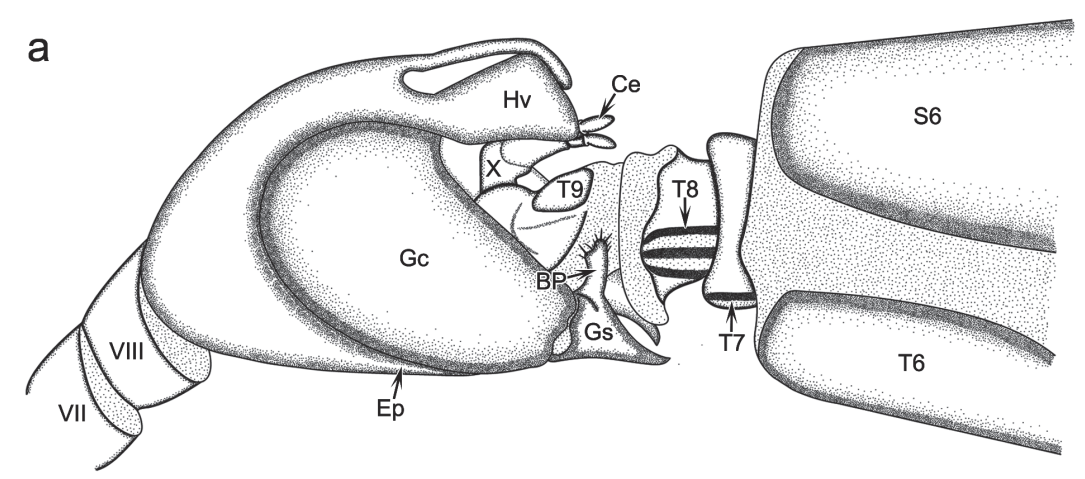

b

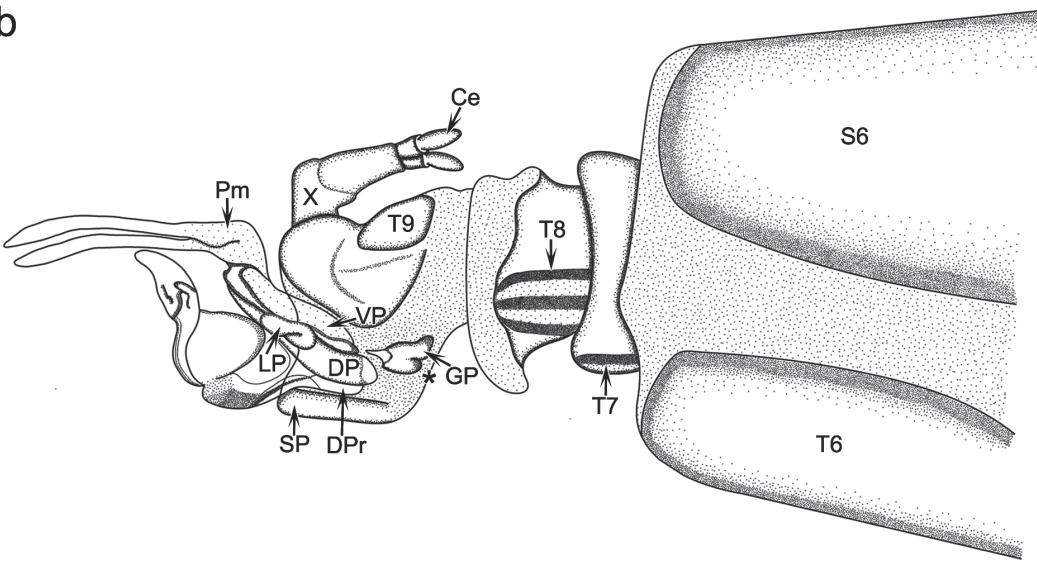

Fig. 4. Schematic drawings of the coupling status of Panorpodes kuandianensis. a, schematic drawing of the male grasps the abdominal end of female by grasping devices; b, schematic drawing of the aedeagus and the genital plate contact in the female genital chamber in copulation. BP, basal process; $\mathrm{Ce}$, cercus; $\mathrm{DP}$, dorsal paramere; DPr, dorsal process; Ep, epandrium; GP, genital plate; Gc, gonocoxite; Gs, gonostylus; Hv, hypovalve; LP, lateral process; Pm, paramere; SP, subgenital plate; S6, sternum VI; T6-T9, tergum VI-IX; VP, ventral paramere; *, the position of the basal tooth clamping the genital chamber. sustain a V-shape mating position. When the mating position changes to end-to-end, A7 of the female is twisted a very small angle, A8 is twisted $\sim 60^{\circ}$ (Figs 4 , $5 \mathrm{c}, \mathrm{b}$ ) and A9 is twisted $\sim 120^{\circ}$ (Figs $4,5 \mathrm{~d}$ ). The torsion of the female abdomen results from the deformation of the intersegmental membrane.

\section{Discussion}

This research is likely the first attempt to describe the mating behavior and the copulatory mechanism of the genus Panorpodes in Panorpodidae. P. kuandianensis is unique in mating behavior for the male and female to change the mating position from a $\mathrm{V}$-shape to an endto-end by temporarily twisting the female abdomen by $180^{\circ}$. Some specialized structures (such as the basal processes and basal teeth) play important roles in obtaining and maintaining a successful mating. This unique mating pattern is remarkably different from that of other Mecoptera studied (Cooper, 1974; Thornhill,
1981; Byers and Thornhill, 1983; Thornhill and Sauer, 1991; Byers, 1997; Ma et al., 2010; Zhong and Hua, 2013; Zhong et al., 2015a, b).

The genital and non-genital grasping devices are usually modified in internally inseminating species of insects to maintain the firm coupling of genitalia between the two sexes (Arnqvist, 1997; Matthews and Matthews, 2010; Chapman, 2013; Zhong et al., 2015a; Richmond et al., 2016), such as the specialized abdominal apparatus in water striders (Arnqvist and Rowe, 2002; Perry and Rowe, 2012) and the notal organ in scorpionflies (Mickoleit, 1971; Thornhill and Sauer, 1991; Zhong and Hua, 2013). The basal processes of gonostyli can restrict the movement of the female genital segments in P. kuandianensis, but are used to impede the genital plate from retreating in Neopanorpa longiprocessa (Zhong and Hua, 2013). The hypandrium with incrassate processes of Panorpodes likely plays a part in stimulating the cerci of the female during mating. A similar phenomenon is also reported in Panorpidae species (Zhong and Hua, 2013; Zhong et al., 2015a). 

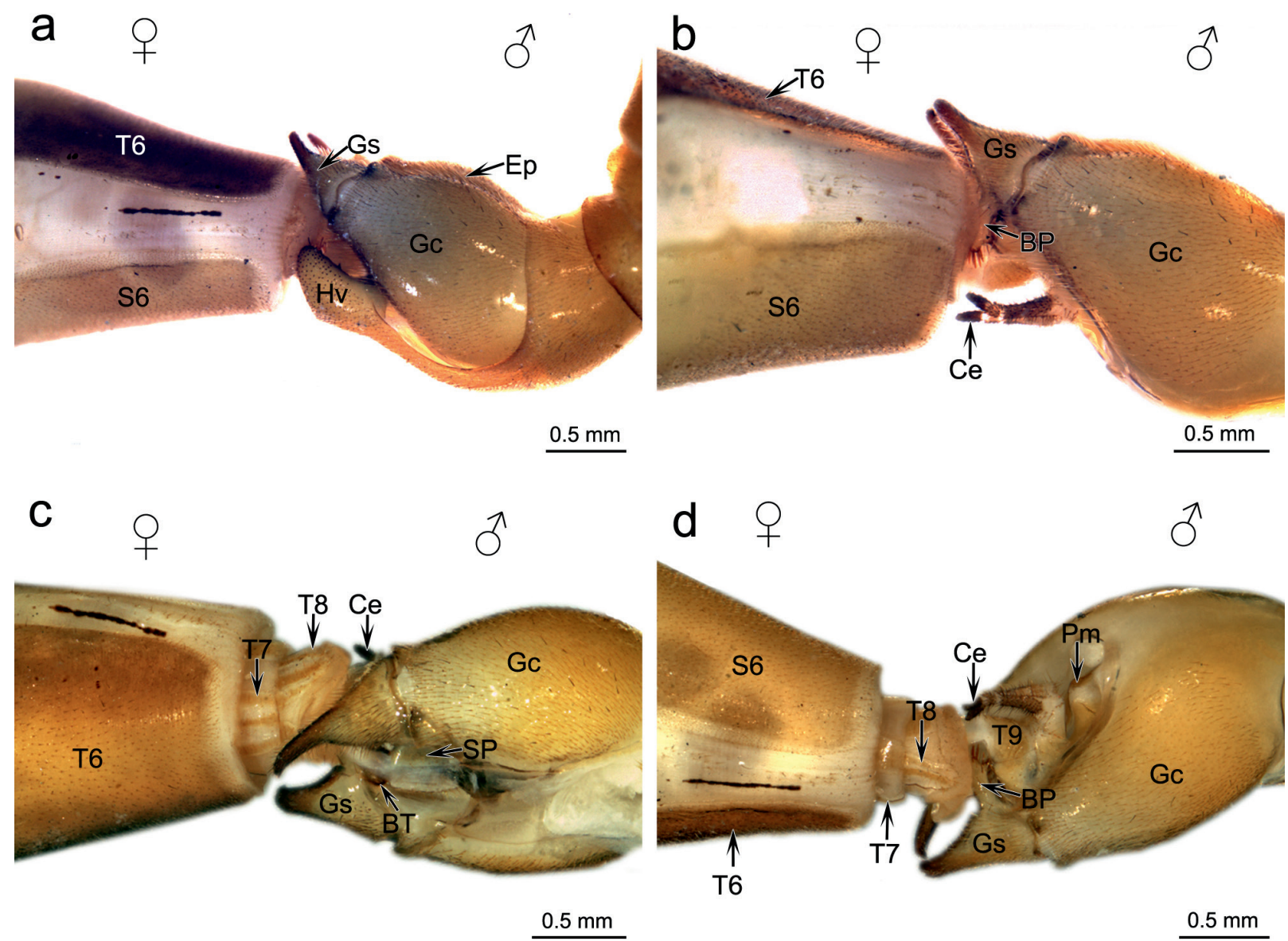

Fig. 5. Coupling genitalia and torsion of the female abdomen. a, coupling genitalia in lateral view; b, the same, with the hypandrium removed to show the cerci of the female and the basal process of the male; c, the torsion of the female abdominal segments VII-VIII, lateral view, with the epandrium removed to show the subgenital plate of the female and the basal tooth of the male; $d$, the torsion of the female abdominal segments VII-IX, lateral view. BP, basal process; BT, basal tooth; Ce, cercus; Ep, epandrium; Gc, gonocoxite; Gs, gonostylus; Hv, hypovalve; Pm, paramere; SP, subgenital plate; S6, sternum VI; T6-T9, tergum VI-IX.

Flexion and rotation of the abdomen are considered to be adaptations for mating and storing the abdominal segments when not in use (McAlpine et al., 1981), and take place in the male terminal abdomen in the majority of insects. Well-known examples are the males of Diptera, the abdomens of which twist from $90^{\circ}$ to $360^{\circ}$ around the long axis of the abdomen to adapt the diverse mating positions (McAlpine et al., 1981; Bickel, 1990; Huber et al., 2007). For the reason of abdominal rotation, Bickel (1990) suggests that female sexual selection pressure promotes the rotation of male abdomen and encourages the circumversion of the terminal abdomen to couple in a male-above position, because a male on top of the female may not only grasp his mate more securely and control the timing of disengagement, but is also able to fend off any intruding males or to stimulate the female using his legs and mouthparts. By contrast, however, in $P$. kuandianensis the torsion occurs in the female. This phenomenon may be correlated with the abdominal morphologies of both sexes. The segments A7-A9 are thick and short in the male, but slender and concealed within A6 in the female (Zhong et al., 2011). In this case, it seems more convenient to rotate the female than the male abdomen. We suggest that during the copulation of insects either the active rotation in the male abdomen or the passive rotation in the female abdomen seems to have evolved to adapt to the sexual conflict, and is mainly beneficial to the male to dominate the mating process. 
The position-changed mating is unusual in Mecoptera (Mickoleit, 1971; Cooper, 1974; Thornhill, 1981; Thornhill and Sauer, 1991; Byers, 1997; Gao and Hua, 2013; Zhong and Hua, 2013; Zhong et al., 2015a, b), but is common in Orthoptera (Alexander and Otte, 1967), Diptera (McAlpine et al., 1981), and Lepidoptera (Scott, 1986; Fänger and Naumann, 1998). The initial side-byside mating position is sustained by the majority of Lepidoptera species, and changes to end-to-end immediately or shortly after establishing genital contact (Scott, 1986; Fänger and Naumann, 1998). For the possible reasons of the position-changed mating, McAlpine and Munroe (1968) believe that the initial position in Diptera is used to establish the interlock of their genitalia and usually takes place during flight. The secondary position is needed to continue copulation and transfer sperm and frequently occurs while the pair rests on a substrate. The position-changed mating in Panorpodes is likely an effective strategy of the male to dominate the mating and to compensate for the lacking of a notal organ, because the end-to-end mating position is frequently accompanied by the pulling behavior. At the pulling phase, the female is almost helpless, and the locomotion of the coupled pair usually depends on the male. This mating pattern may be best explained as a male strategy against female disengagement by turning away. However, details of the contact of the phallotreme of the male and the copulatory pore of the female have not been observed in this study. It may require subsequent preparations of histological serial sections and 3D reconstructions as applied in the fruit fly (Mattei and Wolfner, 2016) and the bushcricket (Wullf et al., 2015).

\section{Acknowledgements}

We thank Ji-Shen Wang for processing photographs. We are grateful to Wen Zhong for comments on the early draft of the manuscript. We also thank the two anonymous reviewers for their helpful comments and valuable suggestions on the revision of the manuscript. The research was financially supported by the National Natural Science Foundation of China (Grant no. 31672341).

\section{References}

Alexander RD, Otte D. 1967. The evolution of genitalia and mating behavior in crickets (Gryllidae) and other Orthoptera. Miscellaneous Publications of the Museum of Zoology, University of Michigan 133: 5-62.

Arnqvist G. 1997. The evolution of animal genitalia: distinguishing between hypotheses by single species studies. Biological Journal of the Linnean Society 60: 365-379.
Arnqvist G, Rowe L. 2002. Correlated evolution of male and female morphologies in water striders. Evolution 56: 936-947.

Bickel DJ. 1990. Sex with a twist in the tail. New Scientist 127: 34-37.

Byers GW. 1997. Biology of Brachypanorpa (Mecoptera: Panorpodidae). Journal of the Kansas Entomological Society 70 : 313-322.

Byers GW. 2002. Scorpionflies, hangingflies, and other Mecoptera. Kansas School Naturalist 48: 3-15.

Byers GW. 2005. Panorpodes discovered in North America (Mecoptera: Panorpodidae). Journal of the Kansas Entomological Society 78: 71-74.

Byers GW, Thornhill R. 1983. Biology of the Mecoptera. Annual Review of Entomology 28: 203-228.

Carpenter FM. 1953. The biology of Brachypanorpa (Mecoptera). Psyche 60: 28-36.

Chapman RF. 2013. The insects: structure and function. 5th ed. Cambridge: Cambridge University Press.

Chapman T, Arnqvist G, Bangham J, Rowe L. 2003. Sexual conflict. Trends in Ecology and Evolution 18: 41-47.

Cooper KW. 1974. Sexual biology, chromosomes, development, life histories and parasites of Boreus, especially of B. notoperates, a southern California Boreus, II. (Mecoptera: Boreidae). Psyche 81: 84-120.

Engqvist L. 2007. Sex, food and conflicts: nutrition dependent nuptial feeding and pre-mating struggles in scorpionflies. Behavioral Ecology and Sociobiology 61: 703-710.

Engqvist L. 2009. Should I stay or should I go? Condition- and status-dependent courtship decisions in the scorpionfly $\mathrm{Pa}$ norpa cognata. Animal Behaviour 78: 491-497.

Engqvist L. 2011. Male attractiveness is negatively genetically associated with investment in copulations. Behavioral Ecology 22: 345-349.

Engqvist L, Sauer KP. 2001. Strategic male mating effort and cryptic male choice in a scorpionfly. Proceedings of the Royal Society B: Biological Sciences 268: 729-735.

Engqvist L, Sauer KP. 2003. Influence of nutrition on courtship and mating in the scorpionfly Panorpa cognata (Mecoptera, Insecta). Ethology 109: 911-928.

Fänger H, Naumann CM. 1998. Genital morphology and copulatory mechanism in Zygaena trifolii (Esper, 1783) (Insecta, Lepidoptera, Zygaenidae). Acta Zoologica (Stockholm) 79: 9-24.

Friedrich F, Pohl H, Beckmann F, Beutel RG. 2013. The head of Merope tuber (Meropeidae) and the phylogeny of Mecoptera (Hexapoda). Arthropod Structure \& Development 42: 69-88.

Gao QH, Hua BZ. 2013. Co-evolution of the mating position and male genitalia in insects: a case study of a hangingfly. PLoS ONE 8: e80651.

Hu GL, Hua BZ. 2016. Historical biogeography of the short-faced scorpionflies (Insecta: Mecoptera: Panorpodidae). Journal of Biogeography 43: 1762-1772.

Huber BA. 2010. Mating positions and the evolution of asymmetric insect genitalia. Genetica 138: 19-25.

Huber BA, Sinclair BJ, Schmitt M. 2007. The evolution of asymmetric genitalia in spiders and insects. Biological Reviews 82: 647-698.

Jiang L, Yue C, Hua BZ. 2014. Larval morphology of Panorpodes kuandianensis (Insecta, Mecoptera, Panorpodidae) and its evolutionary implications. ZooKeys 398: 69-82. 
Kock D, Engels S, Fritsche C, Sauer KP. 2009. Sexual coercion in Panorpa scorpionflies? - The function of the notal organ reconsidered. Behavioral Ecology 20: 639-643.

Krzeminski W, Soszynska-Maj A. 2012. A new genus and species of scorpionfly (Mecoptera) from Baltic amber, with an unusually developed postnotal organ. Systematic Entomology 37: 223-228.

Ma N, Hua BZ. 2011. Structural evidence why males of Panorpa liui offer prey rather than salivary mass as their nuptial gift. Acta Zoologica 92: 398-403.

Ma N, Zhong W, Hua BZ. 2010. Genitalic morphology and copulatory mechanism of the scorpionfly Panorpa jilinensis (Mecoptera: Panorpidae). Micron 41: 931-938.

Mattei AL, Wolfner M. 2016. Drosophila mating, inside and out. Molecular Reproduction and Development 83: 653.

Matthews RW, Matthews JR. 2010. Insect behavior. 2nd ed. London: Springer.

McAlpine JF. 1981. Morphology and terminology - adults. Manual of Nearctic Diptera. Volume 1 (eds. McAlpine JF, Peterson BV, Shewell GE, Teskey HJ, Vockeroth JR, Wood DM). Research Branch Agriculture Canada 27: 9-63.

McAlpine JF, Munroe DD. 1968. Swarming of lonchaeid flies and other insects, with descriptions of four new species of Lonchaeidae (Diptera). The Canadian Entomologist 100: 1154-1178.

Mickoleit G. 1971. Zur phylogenetischen und funktionellen Bedeutung der sogenannten Notalorgane der Mecoptera (Insecta, Mecoptera). Zeitschrift für Morphologie der Tiere 69: 1-8

Parker GA. 2006. Sexual conflict over mating and fertilization: an overview. Philosophical Transactions of the Royal Society B: Biological Sciences 361: 235-259.

Perry JC, Rowe L. 2012. Sexual conflict and antagonistic coevolution across water strider populations. Evolution 66: 544-557.

Pollmann C, Misof B, Sauer KP. 2008. Molecular phylogeny of panorpodid scorpionflies: an enigmatic, species-poor family of Mecoptera (Insecta). Organisms Diversity \& Evolution: 77-83.

Richmond MP, Park J, Henry CS. 2016. The function and evolution of male and female genitalia in Phyllophaga Harris scarab beetles (Coleoptera: Scarabaeidae). Journal of Evolutionary Biology 29: 2276-2288.

Sauer KP, Lubjuhn T, Sindern J, Kullmann H, Kurtz J, Epplen C, Epplen JT. 1998. Mating system and sexual selection in the scorpionfly Panorpa vulgaris (Mecoptera: Panorpidae). Naturwissenschaften 85: 219-228.

Scott JA. 1986. The butterflies of North America: a natural history and field guide. Stanford: Stanford University Press.

Tan JL, Hua BZ. 2008. The second species of the Chinese Panorpodidae (Mecoptera), Panorpodes brachypodus sp. nov. Zootaxa 1751: 59-64.

Thornhill R. 1973. The morphology and histology of new sex pheromone glands in male scorpionflies, Panorpa and Brachypanorpa (Mecoptera: Panorpidae and Panorpodidae). Great Lakes Entomologist 6: 47-55.

Thornhill R. 1980. Rape in Panorpa scorpionflies and a general rape hypothesis. Animal Behaviour 28: 52-59.

Thornhill R. 1981. Panorpa (Mecoptera: Panorpidae) scorpionflies: systems for understanding resource-defense polygyny and alternative male reproductive efforts. Annual Review of Ecology and Systematics 12: 355-386.

Thornhill R, Sauer KP. 1991. The notal organ of the scorpionfly (Panorpa vulgaris): an adaptation to coerce mating duration. Behavioral Ecology 2: 156-164.

Willmann R. 1987. The phylogenetic system of the Mecoptera. Systematic Entomology 12: 519-524.

Wulff NC, Lehmann AW, Hipsley CA, Lehmann GU. 2015. Copulatory courtship by bushcricket genital titillators revealed by functional morphology, $\mu \mathrm{CT}$ scanning for $3 \mathrm{D}$ reconstruction and female sense structures. Arthropod Structure \& Development 44: 388-397.

Zhong W, Ding G, Hua BZ. 2015a. The role of male's anal horns in copulation of a scorpionfly. Journal of Zoology 295: 170177.

Zhong W, Hua BZ. 2013. Mating behaviour and copulatory mechanism in the scorpionfly Neopanorpa longiprocessa (Mecoptera: Panorpidae). PLoS ONE 8: e74781.

Zhong W, Qi ZY, Hua BZ. 2015b. Atypical mating in a scorpionfly without a notal organ. Contributions to Zoology 84: 305315.

Zhong W, Zhang JX, Hua BZ. 2011. Panorpodes kuandianensis, a new species of short-faced scorpionflies (Mecoptera, Panorpodidae) from Liaoning, China. Zootaxa 2921: 47-55.

Received: 20 January 2017

Revised and accepted: 3 May 2017

Published online: 23 October 2017

Editor: Herman de Jong 